doi: https://doi.org/10.15407/dopovidi2018.11.055

УДК 550.34 .013

\title{
С.В. Микуляк
}

Інститут геофізики ім. С.І.Субботіна НАН України, Київ

E-mail:mykulyak@ukr.net

\section{Блоково-ієрархічна модель сейсмічних процесів}

Представлено академіком НАН Украӥни В.І. Старостенком

Побудована модель на основі клітинних автоматів, яка враховує дві фундаментальні властивості сейсмоактивних областей: блоково-ієрархічну будову та перебування їх у стані самоорганізованої критичності. Модель відтворює основні емпіричні закономірності сейсмічних процесів: частотно-енергетичну інваріантність сейсмічних подій (закон Гутенберга-Ріхтера), узагальнений закон Оморі для афтершоків та фрактальний розподіл гіпоцентрів (епіщентрів) зі степеневою залежністю кількості подій від відстані між гіпоцентрами (епіцентрами).

Ключові слова: сейсмічний процес, блокове ієрархічне середовище, самоорганізована критичність.

Земна літосфера - це суттєво неоднорідне структуроване середовище: вона сформована ієрархічною системою об'ємів (блоків), розділених тонкими граничними областями, які, у свою чергу, є блоками нижчого рівня і які також розділені відповідними тонкими областями і т. д. [1]. Така ієрархія охоплює масштаб від тисяч кілометрів (тектонічні плити) до міліметрів (гранули у гірських породах). Особливо яскраво ця блоково-ієрархічна структура проявляється у сейсмоактивних областях, які є граничними зонами, що розділяють найбільші блоки літосфери - тектонічні плити. Завдяки руху тектонічних плит до сейсмоактивних зон неперервно підводиться кінетична енергія, яка накопичується у вигляді пружної енергії, а згодом вивільняється у вигляді землетрусів, та частково дисипує у тепло. Для такого сейсмічного процесу встановлено ряд емпіричних закономірностей, для яких характерна масштабна інваріантність (вони мають вигляд степеневої залежності): закон Гутенберга-Ріхтера (ГР), який зв’язує кількість землетрусів з їх магнітудою [2]; закон Оморі, який описує затухання афтершоків [3], та степеневий закон розподілу епіцентрів, що свідчить про фрактальний розподіл землетрусів у просторі [4]. Землетруси також демонструють далекодіючі просторово-часові кореляції та існування просторово-часових кластерів [5].

Ієрархічна структурованість, обмін енергією із зовнішнім середовищем, відсутність масштабу у сейсмічних процесів визначає необхідність розглядати сейсмоактивну зону як складну ієрархічну, відкриту в термодинамічному сенсі систему, а масштабна інваріантність

(C) С.В. Микуляк, 2018

ISSN 1025-6415. Допов. Нащ. акад. наук Укр. 2018. № 11 
сейсмічних процесів свідчить про те, що система перебуває в критичному стані. Бак із співавт. [6] змоделювали поведінку гірки піску як поведінку системи, що перебуває у критичному стані і яка самопідстроюється таким чином, щоб знаходитись у цьому стані неперервно. Вони назвали такий стан системи самоорганізованою критичністю (СОК). Концепцію СОК для моделювання землетрусів застосовували ряд дослідників [7-9]. Переважна більшість цих моделей базується на моделі блоків з пружинами Барріджа-Кнопова [10], яка складається з жорстких блоків, розташованих на шорсткій горизонтальній поверхні, з пружними зв’язками між собою. Зверху блоки за допомогою пружин приєднані до рухомої площини. При перевищенні одним із блоків порогового значення сили він починає рухатися, змінюючи силу взаємодії сусідніх блоків з шорсткою поверхнею. Рандл, Джексон та Браун (РДБ) [11] модифікували цю модель в модель клітинних автоматів, яка потім була трансформована Оламі, Федером, Крістенсеном (ОФК) [9] в форму гратки. Інша частина СОК моделей з самого початку побудована на основі клітинних автоматів [7, 12].

Традиційні моделі СОК ускладнювалися й удосконалювалися з тим, щоб краще описувати як ГР скейлінг, так і кореляції землетрусів у просторі та часі, які виражаються в існуванні форшоків та афтершоків, а також у їх фрактальному розподілі. Іто та Матсузакі [8] модифікували модель клітинних автоматів за допомогою простої процедури перерозподілу сил після кожного землетрусу так, що будь-який землетрус може ініціювати афтершоки. У ряді моделей, заснованих на РДБ та ОФК моделях, просторово-часові кореляції в сейсмічному процесі досягаються за допомогою введення відповідних неоднорідностей [13].

У стандартних моделях клітинних автоматів усі комірки мають однаковий розмір, так само як у моделях блоків з пружинами всі блоки однакові. Автори роботи [12] розглянули СОК модель клітинних автоматів з ієрархічною будовою сітки, а саме з фрактальним розподілом за розміром комірок. Проте у цій моделі розбиття сітки на комірки є регулярним.

У даній роботі запропонована модель, яка враховує ієрархічну будову сейсмічної зони і той факт, що вона знаходиться у стані самоорганізованої критичності. Сейсмічна область $\Omega$ у вигляді куба утворена ієрархічною системою блоків кубічної форми, які розташовуються у випадковому порядку (рис. 1). Тут не розв’язується конкретна крайова задача, а досліджується можливість моделювання природного сейсмічного процесу за допомогою ієрархічної системи блоків. У систему ззовні підводиться енергія, яка накопичується в блоках нерівномірно. Досягнувши порогового значення, енергія блока вивільняється і передається найближчим сусідам. Частина цієї енергії дисипує, а частина випромінюється в навколишнє середовище. Якщо сусідній блок отримує достатньо енергії, щоб перевищити порогове значення, то він також вивільняє ㄲi i, таким чином, процес вивільнення енергії набуває лавиноподібного характеру, що, власне, і є сейсмічною подією. Використання енергії як основної змінної має перевагу, оскільки енергія є скалярною величиною. Це дає можливість легко застосувати схему клітинних автоматів для формалізації процесу перерозподілу енергії між блоками.

Розглядається ієрархічна система, утворена блоками п’яти розмірів (рівнів) із розмірами сторін $l_{i}$, де $l_{i}$ - цілі числа. Найменші блоки мають розмір $l_{1}=1$, а розмір блоків кожного наступного рівня вдвічі більший. Кількість блоків кожного рівня вибирається із умови того, що фрактальна розмірність блокового середовища дорівнює $D=2,5$, що властиво для розподілів фрагментів більшості природних структурованих матеріалів [12], а саме 
$N_{i}\left(>l_{i}\right)=C_{l} l_{i}^{-D}$, де $N_{i}$ - кількість блоків з розміром більш ніж $l_{i}$. Як і в класичних моделях клітинних автоматів [6-9], кожен блок знаходиться у двох станах: у стані спокою (стійкий елемент) та у збуреному стані (нестійкий елемент). Якщо накопичена блоком енергія менша порогового значення $E_{i}^{t h}$, то такий елемент стійкий, а якщо енергія блока досягає або перевищує порогове значення $E_{i} \geqslant E_{i}^{t h}$, то він втрачає стійкість і зменшує свою енергію. На відміну від класичних моделей клітинних автоматів, у процесі розвантаження блок втрачає тільки частину енергії, яку він накопичив раніше: $E_{i} \rightarrow E_{i}^{r}=E_{i}^{t h} \theta$, де залишкова енергія $E_{i}^{r}$ визначається параметром $\theta$. Оскільки частина енергії дисипує та випромінюється у вигляді сейсмічних хвиль, сусіднім блокам передається енергія $\left(E_{i}-E_{i}^{t h} \theta\right)(1-\gamma \psi)$, де

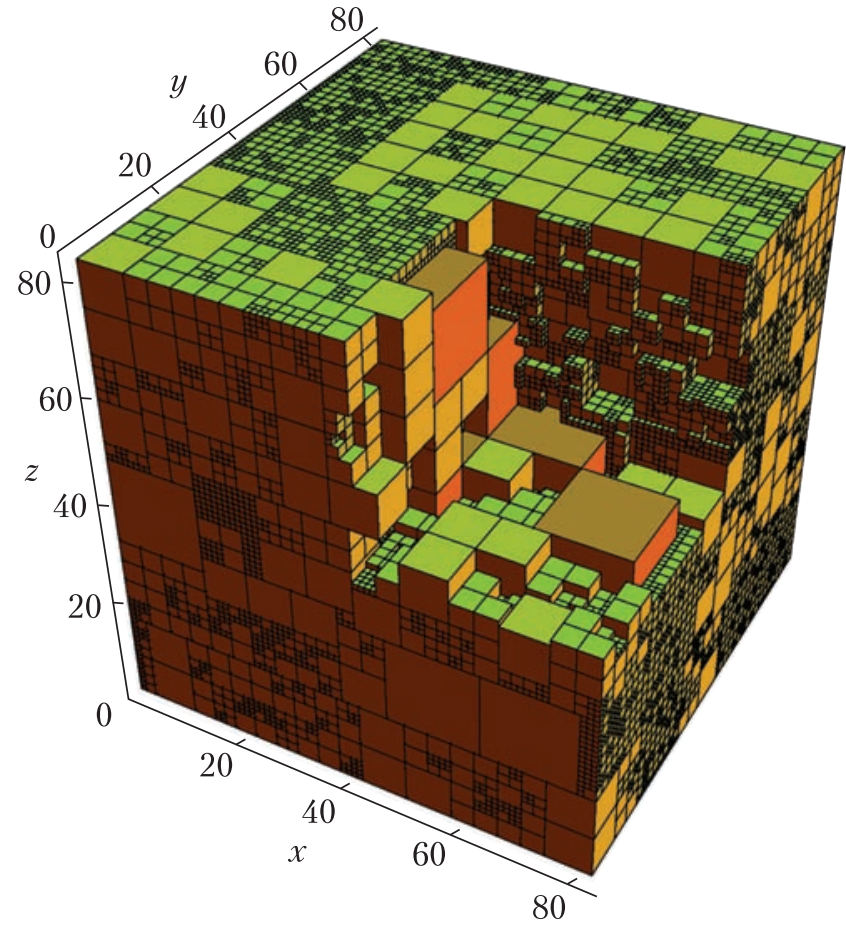

Puc. 1. Сейсмічна область $\Omega$ як ієрархічна система блоків $\psi \in[0,1]-$ випадкова величина, а $\gamma$ - коефіцієнт, який визначає, що частина енергії дисипує та випромінюється. Ця енергія розподіляється між сусідніми блоками пропорційно площі контакту

$$
E_{k} \rightarrow E_{k}+\frac{\lambda_{i k} E_{i}^{t h}}{S_{i}^{2}}\left(E_{i}-E_{i}^{t h} \theta\right)(1-\gamma \chi),
$$

де $\lambda_{i k}-$ площа контакту між $i$-м та $k$-м блоками, $S_{i}=6 l_{i}^{2}$. Порогове значення енергії блока $E_{i}^{t h}$ залежить від його розміру, а саме від його площі поверхні: $E_{i}^{t h}=S_{i}\left(1+\delta_{i}\right)$. Тут введено невеликий шум $\delta_{i}$ з гаусівським розподілом, з нульовим середнім значенням $\left\langle\delta_{i}\right\rangle=0$ та дисперсією $d_{\delta}$.

Енергія вводиться в систему блоків дискретно: порціями $\Delta E=1$ на одному кроці за часом, аналогічно тому, як це здійснюється в моделях клітинних автоматів [7, 12]. Імовірність попадання енергії пропорційна площі поверхні блока. У процесі підготування та реалізації землетрусу слід виділити два різні за швидкістю перебігу процеси: “повільний”, зв’язаний з надходженням енергії в сейсмічну зону від руху тектонічних плит, та “швидкий”, зв’язаний безпосередньо із землетрусом. Тому енергія вводиться в систему тільки під час “повільного” процесу. Накопичення пружної енергії відбувається, коли землетруси відсутні.

На межах задаються періодичні умови, що дає можливість максимально зменшити вплив розміру розрахункової області на сейсмічний процес. У такому випадку вивід енергії відбувається виключно через дисипацію та сейсмічне випромінювання. Моделювання сейсмічного процесу здійснюється в блоковій системі, в якій кількість найбільших блоків $\left(n_{5}\right)$ становить 50, а загальна кількість всіх блоків $(N)$ з урахуванням фрактальної розмірності $D=2,5$ дорівнює 62182 . 

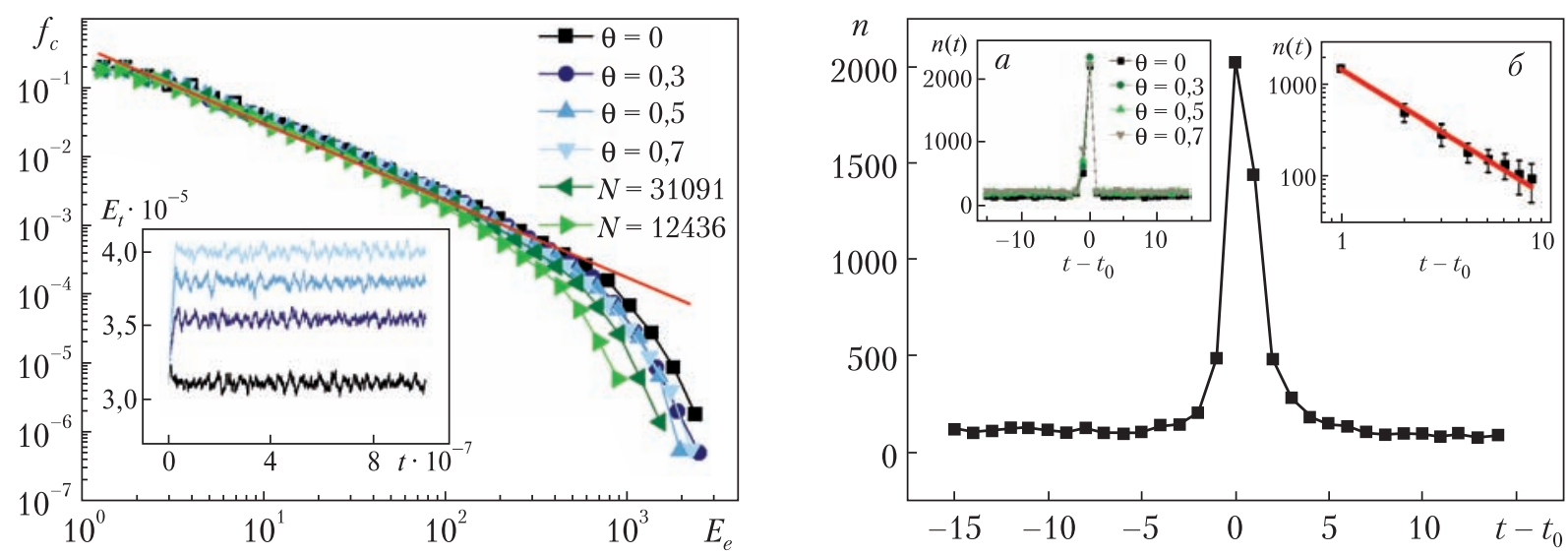

Puc. 2. Кумулятивний розподіл кількості землетрусів за енергією для різних значень залишкової енергії та різної кількості блоків. Нахил прямої, що апроксимує всі залежності, $\beta=1,07$

$\boldsymbol{P u c . 3 . ~ З а л е ж н і с т ь ~ с е р е д н ь о і ̈ ~ к і л ь к о с т і ~ з е м л е т р у с і в ~ в і д ~ ч а с у ~ д о ~ о с н о в н о г о ~ з е м л е т р у с у ~ з а ~ р і з н и х ~ з н а ч е н ь ~ з а - ~}$ лишкової енергії: $a$ - модель без вдосконалення, $\sigma$ - степенева апроксимація афтершоків з використанням вдосконаленої моделі; довірчі інтервали відповідають довірчій імовірності 95 \%

На початку розрахунку всі блоки мають певну енергію, розподілену випадковим чином так, що в жодному блоці вона не перевищує порогового значення. Досить швидко система досягає стаціонарного, але нерівноважного стану з невеликими флуктуаціями сумарної енергії, як показано у вставці на рис. 2. Тут наведені залежності сумарної енергії від часу для чотирьох значень коефіцієнта $\theta$, яким регулюється залишкова енергія $E_{i}^{r}$. Зрозуміло, що найбільшу сумарну енергію має система з найбільшою залишковою енергією.

На рис. 2 показано кумулятивний розподіл землетрусів для чотирьох значень залишкової енергії. Тут пряма лінія відповідає значенню показника $b=1,07 \pm 0,02$, тобто модель 3 хорошою точністю відтворює закон ГР в енергетичному представленні $N(>E) \propto E^{-b}$, в якому показник степеня $b$ знаходиться в діапазоні 0,80-1,05 [9] для всіх значень залишкової енергії. Відхилення від степеневої залежності має місце як для великих землетрусів, так і для малих, що пов'язано з обмеженням розмірів блоків. Це підтверджується тим, що зменшення кількості блоків призводить до більшого загинання функції розподілу.

Сейсмічна активність до та після великих землетрусів для різних значень залишкової енергії вказує на відсутність серій афтершоків, хоча при цьому присутні форшоки (рис. 3 , a). Тому дана модель вимагає удосконалення з тим, щоб описати реалістичну картину сейсмічного процесу, яка включала б існування афтершоків. Для цього слід використати гіпотезу, що великі землетруси спричинюють значне руйнування гірського масиву та перерозподіл напруження в області, охопленій цими землетрусами. Руйнування гірської породи призводить до зменшення критичного напруження (енергії), яке визначає умови втрати рівноваги та генерування афтершоків. У цій моделі зменшення критичної енергії здійнюється за допомогою такої процедури: на кожному часовому кроці для кожного блока, який знаходиться в цій області, випадковим чином зменшується поріг

$$
E_{i}^{t h} \rightarrow \mu E_{i}^{t h}\left(1+\varepsilon_{i}\right),
$$




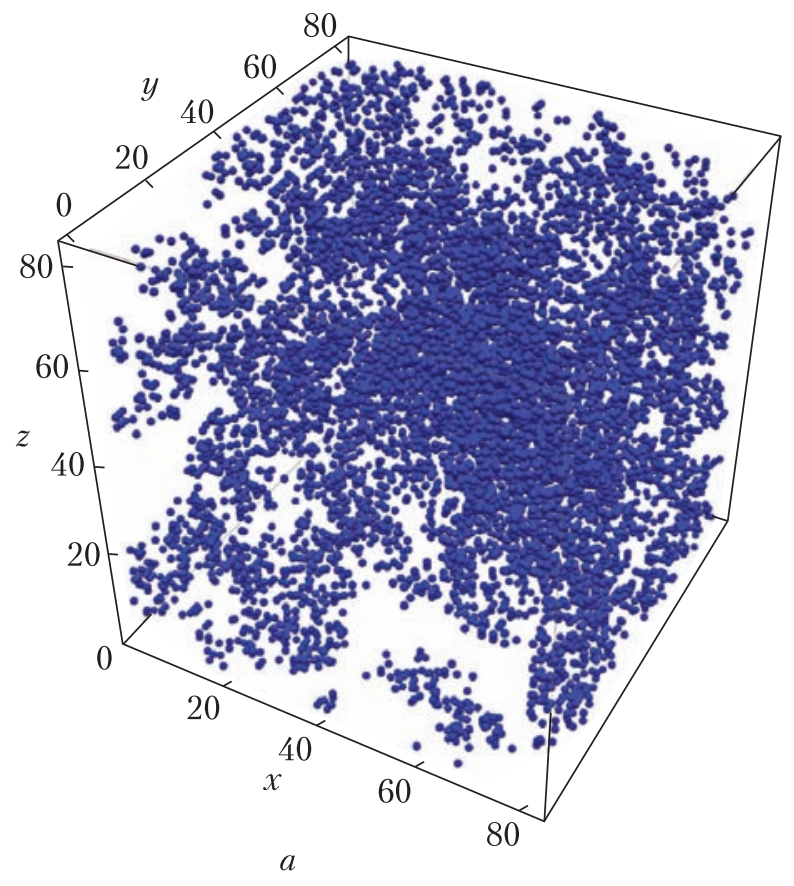

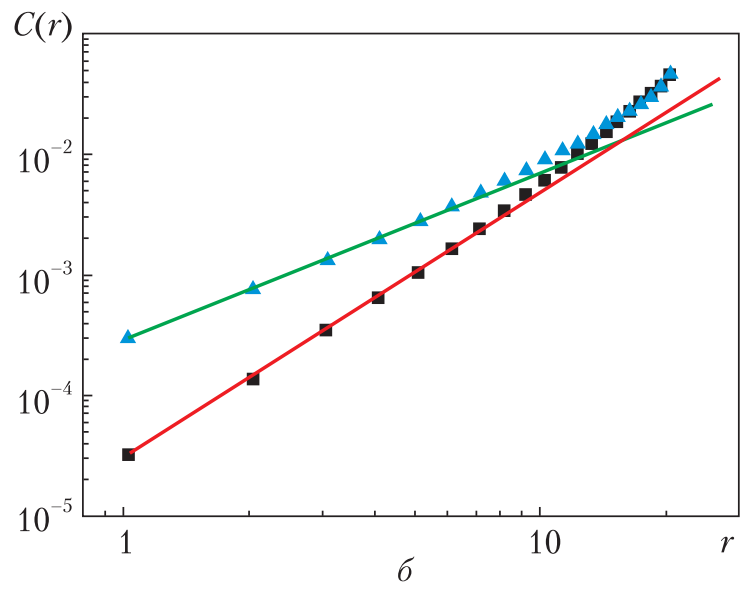

Puc. 4. Об'ємний розподіл землетрусів в області $\Omega(a)$ та кореляційний інтеграл як функція відстаней між гіпоцентрами й епіцентрами землетрусів у логарифмічних координатах і відповідні ароксимації степеневими залежностями (б)

де $0<\mu<1$, а $\varepsilon_{i}-$ невеликий шум з гауссівським розподілом, з нульовим середнім значенням та дисперсією $d_{\varepsilon}$. Таке зменшення відбувається доти, поки значення порогової енергії не досягне величини залишкової енергії $E_{i}^{r}=\theta S_{i}\left(1+\delta_{i}\right)$. В подальшому, через деякий значний проміжок часу, відбувається відновлення (“заліковування”) зруйнованих зв’язків. Цей процес відбувається також випадково, коли виконується умова $\chi_{i}<\tau$, де $\chi_{i} \in[0,1]-$ випадкова величина, що генерується для $i$-го блока на кожному кроці по часу після великого землетрусу, а $\tau$ - мала величина, яка забезпечує тривалий період “заліковування”. Оскільки в області, охопленій землетрусом, відбувається зміна енергетичних порогів, то одночасно можуть виникати кілька афтершоків і всі вони враховуються для побудови статистичних залежностей.

Така вдосконалена модель суттєво змінює поведінку системи після великих землетрусів. На рис. 3 наведено отримані в розрахунках кількість форшоків та афтершоків залежно від часу з використанням удосконаленої моделі. Тут великими землетрусами, як і в попередній моделі, вважаються землетруси з енергією, що перевищує $E=1000$, а загальна кількість великих землетрусів $N=1176295$. Ці дані отримані для параметра залишкової енергії $\theta=0,5$, коефіцієнта, що зменшує поріг $\mu=0,6$, дисперсій $d_{\delta}=0,1, d_{\varepsilon}=0,1$ та $\varepsilon=0,01$. Затухання частоти афтершоків in situ відбувається за законом Оморі, який в узагальненій формі має вигляд

$$
n=k /(t+c)^{p},
$$

де показник степеня $p$ знаходится в інтервалі від 1,0 до 1,8, а $c$ - мала величина [3]. Згідно з результатами моделювання, залежність афтершоків від часу апроксимується кривою 3 коефіцієнтами $k=1489, c=0,03, p=-1,5 \pm 0,04$ (див. рис. 3,6 ).

Гіпоцентри та епіцентри землетрусів утворюють у просторі та на поверхні фрактальні множини з розмірностями $d_{f}^{h}$ та $d_{f}^{e}$ відповідно. За даними численних досліджень, фрактальна 
розмірність для епіцентрів змінюється від 1,0 до 1,8, а гіпоцентральна фрактальна розмірність - від 2,2 для поверхневих до 1,5-1,6 для глибинних землетрусів [14]. У даній моделі гіпоцентри визначались як середнє значення положень центрів усіх кубів, які були задіяні у формуванні землетрусу, а епіцентри - відповідно до їх проекції на верхню площину куба $\Omega$.

Аналіз просторового розподілу гіпоцентрів землетрусів (рис. 4, $a$ ) показав, що гіпоцентри розташовані нерівномірно, утворюючи кластери. Фрактальні розмірності $d_{f}^{h}$ та $d_{f}^{e}$ цих розподілів оцінюються за допомогою методу кореляційного інтеграла [15]. Кореляційний інтеграл визначається як

$$
C(r)=\lim _{N \rightarrow \infty} \frac{1}{N^{2}} \sum_{i, j=1, i \neq j}^{N} H\left(r-\left|\mathbf{r}_{i}-\mathbf{r}_{j}\right|\right),
$$

де $\mathbf{r}_{i}$ та $\mathbf{r}_{j}$ - гіпоцентри (епіцентри) $i$-го та $j$-го землетрусів, а $H-$ функція Хевісайда. Тобто для кореляційного інтеграла підраховуються тільки ті землетруси, відстань між якими менша від $r$. Для фрактальних множин кореляційний інтеграл $C(r)$ на малих відстанях $r$ зростає за степеневим законом

$$
C(r) \propto r^{v}
$$

де кореляційний показник, або двоточкова кореляційна розмірність $v$ дуже близька до фрактальної розмірності $d_{f}$. Для $N=1176295$ землетрусів (за такої великої кількості подій кореляційний інтеграл вже не залежить від $N$ ) залежності кореляційного інтеграла від відстані для гіпоцентрів та епіцентрів у подвійних логарифмічних координатах наведено на рис. 4, б. Обчислена за цими залежностями двоточкова кореляційна розмірність для епіцентрів $\left(v^{e}=1,8\right)$ попадає в межі експериментальних величин, а для гіпоцентрів $\left(v^{h}=2,8\right)$ дещо перевищує фрактальні розмірності, отримані для реальних землетрусів. Це пов’язано з тим, що в моделі область має форму куба, а в природних умовах сейсмічні області видовжені вздовж розломів.

Отже, запропонована ієрархічна модель, що базується на самоорганізованій критичності, відтворює основні закономірності сейсмічних процесів: закон Гутенберга-Ріхтера 3 показником степеня $\beta=1,07 \pm 0,02$, закон Оморі для афтершоків з коефіцієнтом затухання $p=1,5 \pm 0,04$, наявність форшоків, фрактальні властивості просторового розподілу землетрусів з фрактальними розмірностями $d_{f}^{h} \approx 2,8$ та $d_{f}^{e} \approx 1,8$ відповідно для гіпоцентрів та епіцентрів. Модель враховує як часові, так і просторові кореляції землетрусів. Слід зауважити, що поза розглядом даної моделі залишилося те, що природне середовище являє собою ієрархічну систему вкладених блоків, а не є системою розташованих випадковим чином блоків. Крім того, не враховується анізотропія сейсмічної зони, пов’язана з існуючими розломами та морфологічною неоднорідністю. Але навіть 3 такою структурою ієрархічного середовища модель досить правильно відтворює характерні властивості сейсмічного процесу.

\section{ЦИТОВАНА ЛІТЕРАТУРА}

1. Садовский М.А., Болховитинов Л.Г., Писаренко В.Ф. О свойствах дискретности горных пород. Изв. АН СССР. Физика Земли. 1982. 12, № 3. С. 3-18. 
2. Gutenberg B., Richter C.F. Seismicity of the Earth and associated phenomena. Princeton: Princeton Univ. Press, 1949. $273 \mathrm{p}$.

3. Utsu T. Aftershocks and earthquake statistics (I): some parameters which characterize an aftershock sequence and their interrelations. Geophysics. 1969. 3, № 3. P. 129-195.

4. Robertson M.C., Sammis C.G., Sahimi M., Martin A.J. Fractal analysis of three-dimensional spatial distributions of earthquakes with a percolation interpretation.J. Geophys. Res. 1995. 100, № B1. P. 609-620. doi: https://doi.org/10.1029/94JB02463

5. Shcherbakov R., Aalsburg J.V., Rundle J.B., Turcotte D.L. Correlations in aftershock and seismicity patterns. Tectonophysics. 2006. 413. P. 53-62. doi: https://doi.org/10.1016/j.tecto.2005.10.009

6. Bak P., Tang C., Wiesenfeld K. Self-organized criticality. Phys. Rev. A. 1988. 38, № 1. P. 364-374. doi: https:// doi.org/10.1103/PhysRevA.38.364

7. Bak P., Tang C. Earthquakes as a self-organized critical phenomenon. J. Geophys. Res. 1989. 94, № B11. P. 15635-15637. doi: https://doi.org/10.1029/JB094iB11p15635

8. Ito K., Matsuzaki M. Earthquakes as self-organized critical phenomena. J. Geophys. Res. 1990. 95, № B5. P. 6853-6860. doi: https://doi.org/10.1029/JB095iB05p06853

9. Olami Z., Feder H.J.S., Christensen K. Self-organized criticality in a continuous, nonconservative cellular automaton modeling earthquakes. Phys. Rev. Lett. 1992. 68, № 8. P. 1244-1247. doi: https://doi.org/10.1103/ PhysRevLett.68.1244

10. Burridge R., Knopoff L. Model and theoretical seismicity. Bull. Seismol. Soc. Am. 1967. 57. P. 341-371.

11. Rundle J.B., Jackson D.D. Numerical simulation of earthquake sequences. Bull. Seismol. Soc. Am. 1977. 67, № 5. P. 1363-1377. doi: https://doi.org/10.1007/BF01329869

12. Barriere B., Turcotte D.L. Seismicity and self-organized criticality. Phys. Rev. E. 1994. 49. P. 1151-1160. doi: https://doi.org/10.1103/PhysRevE.49.1151

13. Dominguez R., Tiampo K.F., Serino C.A., Klein W. Scaling of earthquake models with inhomogeneous stress dissipation. Phys. Rev. E. 2013. 87. 022809. doi: https://doi.org/10.1103/PhysRevE.87.022809

14. Kagan Y.Y. Earthquake spatial distribution: the correlation dimension. Geophys. J. Int. 2007. 168. P. 11751194. doi: https://doi.org/10.1111/j.1365-246X.2006.03251.x

15. Grassbergerg P., Procaccia I. Measuring the strangeness of strange attractors. Physica D: Nonlinear Phenomena. 1983. 9, № 1-2. P. 189-208. doi: https://doi.org/10.1016/0167-2789(83)90298-1

Надійшло до редакції 10.07.2018

\section{REFERENCES}

1. Sadovskiy, M. A., Bolhovitinov, L. G. \& Pisarenko, V. F. (1982). On the properties of the discreteness of rocks. Izv. AN SSSR. Fiz. Zemli ,12, No. 3, pp. 3-18 (in Russian).

2. Gutenberg, B. \& Richter, C. F. (1949). Seismicity of the Earth and associated phenomena. Princeton: Princeton Univ. Press.

3. Utsu, T. (1969). Aftershocks and earthquake statistics (I): some parameters which characterize an aftershock sequence and their interrelations. Geophysics, 3, No. 3, pp. 129-195.

4. Robertson, M. C., Sammis, C. G., Sahimi, M. \& Martin, A. J. (1995). Fractal analysis of three-dimensional spatial distributions of earthquakes with a percolation interpretation. J. Geophys. Res., 100, No. B1, pp. 609620. doi: https://doi.org/10.1029/94JB02463

5. Shcherbakov, R., Aalsburg, J. V., Rundle, J. B. \& Turcotte, D. L. (2006). Correlations in aftershock and seismicity patterns. Tectonophysics, 413, pp. 53-62. doi: https://doi.org/10.1016/j.tecto.2005.10.009

6. Bak, P., Tang, C. \& Wiesenfeld, K. (1988). Self-organized criticality. Phys. Rev. A, 38, No. 1, pp. 364-374. doi: https://doi.org/10.1103/PhysRevA.38.364

7. Bak, P. \& Tang, C. (1989). Earthquakes as a self-organized critical phenomenon. J. Geophys. Res., 94, No. 11, pp. 15635-15637. doi: https://doi.org/10.1029/JB094iB11p15635

8. Ito, K. \& Matsuzaki, M. (1990). Earthquakes as self-organized critical phenomena. J. Geophys. Res., 95, No. B5, pp. 6853-6860. doi: https://doi.org/10.1029/JB095iB05p06853

9. Olami, Z., Feder, H. J. S. \& Christensen, K. (1992). Self-organized criticality in a continuous, nonconservative cellular automaton modeling earthquakes. Phys. Rev. Lett., 68, No. 8, pp. 1244-1247. doi: https://doi. org/10.1103/PhysRevLett.68.1244 
10. Burridge, R. \& Knopoff, L. (1967). Model and theoretical seismicity. Bull. Seismol. Soc. Am., 57, pp. 341-371.

11. Rundle, J. B. \& Jackson, D. D. (1977). Numerical simulation of earthquake sequences. Bull. Seismol. Soc. Am., 67, No. 5, pp. 1363-1377. doi: https://doi.org/10.1007/BF01329869

12. Barriere, B. \& Turcotte, D. L. (1994). Seismicity and self-organized criticality. Phys. Rev. E, 49, pp. 11511160. doi: https://doi.org/10.1103/PhysRevE.49.1151

13. Dominguez, R., Tiampo, K. F., Serino, C. A. \& Klein, W. (2013). Scaling of earthquake models with inhomogeneous stress dissipation. Phys. Rev. E, 87, 022809. doi: https://doi.org/10.1103/PhysRevE.87.022809

14. Kagan, Y. Y. (2007). Earthquake spatial distribution: the correlation dimension. Geophys. J. Int., 168, pp. 1175-1194. doi: https://doi.org/10.1111/j.1365-246X.2006.03251.x

15. Grassbergerg, P. \& Procaccia, I. (1983). Measuring the strangeness of strange attractors. Physica D: Nonlinear Phenomena, 9, No. 1-2, pp. 189-208. doi: https://doi.org/10.1016/0167-2789(83)90298-1

Received 10.07.2018

\section{С.В. Микуляк}

Институт геофизики им. С.И. Субботина НАН Украины, Киев

E-mail: mykulyak@ukr.net

\section{БЛОЧНО-ИЕРАРХИЧЕСКАЯ МОДЕЛЬ СЕЙСМИЧЕСКИХ ПРОЦЕССОВ}

Построена модель на основе клеточных автоматов, учитывающая два фундаментальных свойства сейсмоактивных областей: блочно-иерархическое строение и пребывание их в состоянии самоорганизованной критичности. Модель воспроизводит основные эмпирические закономерности сейсмических процессов: частотно-энергетическую инвариантность сейсмических событий (закон Гутенберга-Рихтера), обобщенный закон Омори для афтершоков и фрактальное распределение гипоцентров (эпицентров) со степенной зависимостью количества событий от расстояния между гипоцентрами (эпицентрами).

Ключевые слова: сейсмический процесс, блочная иерархическая среда, самоорганизованная критичность.

\section{S.V. Mykulyak}

S.I. Subbotin Institute of Geophysics of the NAS of Ukraine, Kiev

E-mail: mykulyak@ukr.net

\section{HIERARCHICAL BLOCK MODEL FOR SEISMIC PROCESSES}

The model based on cellular automata is constructed with regard for two fundamental properties of seismically active areas: a hierarchical block structure and their existence in a state of self-organized criticality. The model reproduces the main empirical properties of seismic processes: the frequency-energy invariance of seismic events (the Gutenberg-Richter law), generalized Omori law for aftershocks, and fractal distribution of hypocenters (epicenters) with power-law dependences of the number of events on distances between hypocenters (epicenters).

Keywords: seismic process, block hierarchical medium, self-organized criticality. 